n.tronos

glyndŵn

Glyndŵr University

Glyndŵr University Research Online

Computing

Computer Science

10-1-2009

\title{
A case study using a methodological approach to developing user interfaces for elderly and disabled people
}

Rich Picking

Glyndwr University,Wrexham, r.picking@glyndwr.ac.uk

Alexia Robinet

Glyndwr University

Vic Grout

Glyndwr University, v.grout@glyndwr.ac.uk

John McGinn

Glyndwr University, j.mcginn@glyndwr.ac.uk

Armando Roy

Glyndwr University

See next page for additional authors

Follow this and additional works at: http://epubs.glyndwr.ac.uk/cair

Part of the Computer and Systems Architecture Commons, Digital Communications and

Networking Commons, Hardware Systems Commons, and the Systems and Communications

Commons

\section{Recommended Citation}

Picking, R., Robinet, A., Grout, V., McGinn, J., Roy, A., Ellis, S. \& Oram, D., (2010) "A case study using a methodological approach to developing user interfaces for elderly and disabled people”. The Computer Journal, Volume 53, Issue 6, pp842-859.

This Article is brought to you for free and open access by the Computer Science at Glyndŵr University Research Online. It has been accepted for inclusion in Computing by an authorized administrator of Glyndŵr University Research Online. For more information, please contact

d.jepson@glyndwr.ac.uk. 


\title{
A case study using a methodological approach to developing user interfaces for elderly and disabled people
}

\begin{abstract}
In this paper, we present a case study on the development of interfaces for elderly and disabled users. The domain of the case study was situated in the home environment, where we focused on producing affordable technologies to enable users to interact with and to control home appliances. We have developed ambient user interfaces that are integrated in familiar home artefacts, such as televisions and digital picture frames. These interfaces are connected remotely to a home network and are adaptive to users' expected increasing physical and cognitive needs. To support the development of the project, we created a novel methodology that is grounded in the ethical issues associated with a project of this nature. Our success with it has led to us presenting it here as a practical approach to developing user interfaces for a range of interactive applications, especially where there may be diverse user populations. This paper describes our journey through this project, how the methodology has been used throughout and the development of our user interfaces and their evaluation.
\end{abstract}

\section{Keywords}

assisted living, vulnerable users, ethical issues

\section{Disciplines}

Computer and Systems Architecture | Computer Engineering | Digital Communications and Networking | Hardware Systems | Systems and Communications

\section{Comments}

Copyright (C) The Author 2009 Published by Oxford University Press on behalf of The British Computer Society, All rights reserved.

This is a pre-copy-editing, author-produced PDF of an article accepted for publication in The Computer Journal following peer review. The definitive publisher-authenticated version Picking, R., Robinet, A., Grout, V., McGinn, J., Roy, A., Ellis, S. \& Oram, D., (2010) "A case study using a methodological approach to developing user interfaces for elderly and disabled people", The Computer Journal, Volume 53, Issue 6, pp842-859 which is available online at: http://dx.doi.org/10.1093/comjnl/bxp089.

\section{Authors}

Rich Picking, Alexia Robinet, Vic Grout, John McGinn, Armando Roy, Simon Ellis, and Denise Oram 


\section{A case study using a methodological approach to developing user interfaces for elderly and disabled people.}

Short title: Developing user interfaces for elderly and disabled people

Paper authors:

Rich Picking, Alexia Robinet, Vic Grout, John McGinn, Armando Roy, Simon Ellis,

Denise Oram

Centre for Applied Internet Research

Glyndwr University, Wrexham, WALES

Corresponding author:

Dr Rich Picking

Principal Lecturer

Centre for Applied Internet Research

Glyndwr University, Wrexham, WALES

LL11 2AW

r.picking@glyndwr.ac.uk

01978293066 


\section{Abstract}

In this paper, we present a case study on the development of interfaces for elderly and disabled users. The domain of the case study was situated in the home environment, where we focused on producing affordable technologies to enable users to interact with and to control home appliances. We have developed ambient user interfaces which are integrated in familiar home artefacts, such as televisions and digital picture frames. These interfaces are connected remotely to a home network and are adaptive to users' expected increasing physical and cognitive needs. To support the project's development, we created a novel methodology which is grounded in the ethical issues associated with a project of this nature. Our success with it has led to us presenting it here as a practical approach to developing user interfaces for a range of interactive applications, especially where there may be diverse user populations. This paper describes our journey through this project, how the methodology has been used throughout, the development of our user interfaces, and their evaluation.

\section{Introduction}

The twenty first century phenomenon known as the demographic time bomb is now well documented, as we experience an increase in the number of elderly people and a reduction of younger people to care for them as they lose their independence in later years. What constitutes 'elderly' is clearly an area of debate, as many people stay healthier in old age than their younger counterparts. However, purely for the sake of clarity in this paper, we use the generally accepted (in western society) age of 65 . In Europe, this population represented around $17 \%$ in 2007 , but is expected to increase 
rapidly. By 2020, the elderly population will represent an estimated $20 \%$, and by 2050 it will be $30 \%$ [1].

This trend has prompted many researchers and developers of information technology to find ways to enable elderly people to live independently for longer. A number of research projects have sought to develop smart home environments to meet the special needs of the ageing population and offer them security, comfort and quality of life $[2,3,4,5]$. Assistive technologies in home environments can help with household tasks, put carers at ease and make sure vulnerable people feel safe in their home. It is well-documented that most elderly people would rather stay in their own home rather than a care home, despite illnesses or impairments that could put their wellbeing at risk [6]. Although assistive technologies incur financial expense, making them affordable would more than offset the cost of nursing home care. The smart home environment can also offer added value, by monitoring long-term changes that may cause health concerns [7]. Such systems could alert carers and family of any significant changes in behaviour, diet, daily tasks or health. Fall detectors, smart pill dispensers, medical equipment to test heart rate and blood pressure, tracking devices, and sensors, all create a potentially safer environment in which to live for people with sensory, cognitive or physical disabilities.

Even though computer systems have already shown that they can be powerful aids in home-health care, their promise to improve the quality of life and independence of elderly people can only be fulfilled if they are designed to take into consideration the specific needs of their users [8]. In order to solve the problems of accessibility for elderly 
users who might have cognitive, physical or other limitations, interchangeable or adaptive interfaces are required. Such interfaces integrated with intelligent agents, known as assistive environments, may act as a substitute for care and benefit elderly users by increasing their level of activity and quality of life. Such developments may also serve to provide younger disabled people with similar benefits, as well as for the wider population in general, in the context of the design for all concept.

We must be mindful however, that designing for vulnerable people raises serious ethical concerns $[9,10,11,12]$. The monitoring of users' activity has many advantages, although this is potentially intrusive [13]. In addition, it has been proposed that it is vital to find the right balance of assistance versus nuisance [14]. Reliance and trust are also central issues [12]. Paradoxically, all the benefits that are offered by assistive technologies may bring negative aspects into the user's life [9]. For example, communication systems which provide alternative ways of communication (video-telephony, email, for example) for people experiencing speech or communication impairment, may reduce direct contact with family or friends. A further negative aspect of such technology is that it may actually promote inactivity. The consequences of introducing bad or inappropriate design can make a difficult situation even worse, so we need to make sure that our approach to the design and the evaluation of the artefacts we produce is as optimal as possible.

This paper presents a case study using a novel methodological approach to the user interface development process, specifically for vulnerable people where ethical issues have particular importance. The domain of the case study is situated in the home 
environment, and is focused on producing affordable technologies to enable users to interact with and to control home appliances. Typical home appliances may pose significant usability problems for users with failing physical and cognitive abilities. In the kitchen for example, washing machines often have complex programmes, food contents in refrigerators and freezers may be difficult to discern (in particular the information on packaging), and ovens can cause serious injury if not used with particular caution. One only has to visit a high street appliances store to become confused by the vast array of varied control panels, displays, and features - many of which sacrifice usability for sleek, fashionable design.

To overcome these usability problems, we have developed consistent, ambient user interfaces which are integrated in familiar home artefacts, such as televisions and digital picture frames. These interfaces are connected remotely to a home network via an intelligent set-top box server called the e-servant. The interfaces are adaptive to users' expected increasing physical and cognitive needs, as the e-servant monitors their interaction over time, and modifies users' personal profiles according to their changing behaviour patterns. The user interface then automatically adapts, both in terms of its look and feel (for example in the case of deteriorating eyesight), and the interaction dialogue (for example, in the case of deteriorating cognitive ability).

\section{Background to the case study}

The case study described here is a component of a wider project called EASYLINE 
PLUS, and involves academic and industrial consortium partners from Wales, England, Spain, and Germany. The aim of the project is to develop a range of advanced white goods, near to market, to support elderly people, with or without disabilities in maintaining a longer independent life by compensating for their loss of physical or cognitive abilities.

Sensors using radio frequency identification (RFID), ZigBee, powerline communication (PLC) and infra-red technologies enable the system to interact with the home environment. Human activity is monitored by an intelligent server, which we have called the e-servant. The e-servant recognizes and adapts to changing needs as the user grows less able over time. This is done using a combination of pre-configured user profiles which are subtley modified by a neural network sub-system. The research presented in subsequent sections of this paper has led us to concentrate on user interfaces situated in modified familiar home devices, specifically television sets and digital photographic frames.

\section{Methodology}

During the initial investigation in how to approach the user interface development for this project, we undertook a critical analysis of the most used methodologies for interface and software development. There is clear agreement among experts in the field of humancomputer interaction for elderly adults that ethical issues must be considered in the design process [15]. Ethical guidelines may be used to accompany methodologies in development and can provide useful sets of principles and duties; however practitioners 
have often had difficulty in applying them [16]. Established methodologies such as Merise [17] and Rapid Application Development (RAD) [18] enable participation of endusers and senior management in the decision cycle, but do not directly integrate ethics in the process. Indeed, most methodologies take little account of ethical issues, or they might be addressed at the initial stages or some part of the process as with Multiview2 [19] where ethical issues form part of the organisational analysis at the start of the project.

In the light of the lack of an existing methodology to support our requirements, we developed a new methodology which we call EDUCATID, an ethically-driven, usercentred approach to interface development. As the acronym suggests, it is grounded in being ethically-driven, in that ethical issues are carefully scrutinized at the initial analysis phase, as well as in iterations of interface prototyping, development and evaluation. Similarly, it is user-centred in that users are involved in participative, narrative workshops in the initial analysis phase and also in the method's iterations, and naturally during the usability evaluation phase.

EDUCATID is a simple, rapid, and practical methodology which adheres to the four basic phases for interface design methods: analysis, design, development and evaluation [20]. Each phase is informed by a fifth element, which we call the user analysis phase. This forms the central hub of the methodology, and involves the elicitation of user narratives as well as ethical and legal inspection. EDUCATID follows a cyclical, prototyping paradigm, where each phase may be iterated any number of times, although 
we recommend a target of three iterations: the first concentrating on prototyping; the second focussing on detailed development; the third being a verification exercise. Each phase contains a number of activities which have specific inputs and outputs, and which are easy to understand, have little or no formality, and which are represented for end-user participation where appropriate.

The EDUCATID methodology is summarized in figures 1a and $1 \mathrm{~b}$. The process begins with requirements analysis. Background and market research are undertaken to establish the feasibility of the development project, and to consider previous work in the application domain. In parallel with the requirements analysis phase, the first instance of the user analysis phase is launched, where an ethical and legal inspection of the anticipated project is undertaken. We propose the use of Oram and Headon's ethical triangle [21], which provides a framework for exposing potential ethical problems throughout the systems development process. The guidelines proposed by Abascal and Nicolle [9] (table 1) can be used in combination with the ethical triangle to provide a practical and valuable ethical audit tool for developers. This approach is presented in further detail in the context of the case study. 


\begin{tabular}{|c|c|c|}
\hline Risks & Description & Guidelines for HCI designers \\
\hline $\begin{array}{l}\text { Design of } \\
\text { inaccessible } \\
\text { devices or } \\
\text { services }\end{array}$ & $\begin{array}{l}\text { Devices or services that } \\
\text { cannot be used by people } \\
\text { with special needs, even } \\
\text { if they have adequately } \\
\text { adapted equipment }\end{array}$ & $\begin{array}{l}\text { Develop a sound study of user needs. } \\
\text { Ensure user participation in the design. } \\
\text { Use guidelines towards a design for all } \\
\text { approach to design. }\end{array}$ \\
\hline Loss of privacy & $\begin{array}{l}\text { When personal } \\
\text { information is stored } \\
\text { and/or transmitted } \\
\text { without the authorisation } \\
\text { of the user }\end{array}$ & $\begin{array}{l}\text { Do not store or transmit personal } \\
\text { information without user awareness } \\
\text { and authorization. } \\
\text { Avoid storing or transmitting } \\
\text { unnecessary personal information. } \\
\text { Use procedures to ensure anonymity } \\
\text { (e.g. pseudonyms). } \\
\text { Use secure means to transmit and store } \\
\text { authorised personal information. }\end{array}$ \\
\hline $\begin{array}{l}\text { Loss of } \\
\text { autonomy }\end{array}$ & $\begin{array}{l}\text { When decisions about the } \\
\text { user are taken by other } \\
\text { than the user or the } \\
\text { person(s) authorised by } \\
\text { the user }\end{array}$ & $\begin{array}{l}\text { Avoid unnecessary automatic or } \\
\text { external decisions by the system. } \\
\text { Inform the user about decisions taken } \\
\text { automatically or externally. } \\
\text { Allow intervention only by authorised } \\
\text { personnel. }\end{array}$ \\
\hline Economic factors & $\begin{array}{l}\text { Devices and services out } \\
\text { of the financial capability } \\
\text { of the users because } \\
\text { 'excessive' technology is } \\
\text { used }\end{array}$ & $\begin{array}{l}\text { Minimise the use of 'fancy' or } \\
\text { expensive technology. } \\
\text { Avoid features not needed by the user } \\
\text { that make the product more expensive } \\
\text { When possible, select the lower cost } \\
\text { choice. }\end{array}$ \\
\hline $\begin{array}{l}\text { Invasive and/or } \\
\text { socially } \\
\text { unacceptable } \\
\text { location systems }\end{array}$ & $\begin{array}{l}\text { Systems for personal } \\
\text { location that invade } \\
\text { personal freedom and/or } \\
\text { devices for location that } \\
\text { are socially unacceptable }\end{array}$ & $\begin{array}{l}\text { Use location systems only with } \\
\text { stakeholders' awareness and consent. } \\
\text { Delete location information after } \\
\text { convenient usage and do not record it } \\
\text { unnecessarily. } \\
\text { Use discrete location devices, use } \\
\text { 'tagging' devices only with strict } \\
\text { ethical considerations. }\end{array}$ \\
\hline
\end{tabular}

Table 1: A first approach to socially and ethically aware design guidelines [9].

The next step of the process involves the second activity in the user analysis phase, namely the user narratives workshop. As in Joint Applications Development [22], this takes place very early in the lifecycle. However, as it is a central activity, it is repeated at 
set points in the process, typically after an instance of the methodology's evaluation phase. The narratives workshop involves end users, as well as technical and domain experts. During this event, typical usage scenarios are identified and described. The outputs from this feed into the task analysis in the requirements analysis phase, documented in the form of use cases. The outputs from the task analysis and background/market research are used to document the user and functional requirements.

As well as providing valuable input into the requirements phase, the workshop outcomes also feed into the conceptual design phase. Here, personas [23] and narrative scenarios, in the form of storyboards, are generated. Personas are then used to create a more formal set of user profiles, which represent the typical range of users of the system. The outputs from the conceptual design phase (user profiles and narrative scenarios) are then combined to form the initial activity of the interface design and build phase, which we term interaction modelling. This activity produces a semi-formalized representation in the form of a pseudocode, which models the tasks users will undertake. Each task is modelled according to every user type, extracted directly from the user profiles. The two remaining activities in the interface design and build phase are user interface design and user interface interaction. User interface design is the physical design of the interface, for example the screens, icons, input and output devices. User interface interaction is the physical execution of the interaction model i.e. the running of the prototype or system itself. Once a testable interface prototype is developed, the evaluation phase is undertaken. This may be in a laboratory and/or field environment, depending on the nature of the application. The results of the evaluation are used to re-visit the original 
requirements, where the cycle of phases begins again. It is imperative at this stage that ethical and legal issues are re-considered, and that a further narratives workshop is organized. The central theme of this engagement is to present the interface prototype and use it to consult with end users and other stakeholders regarding original scenarios. EDUCATID in practice is now described in the context of the EASYLINE PLUS case study.

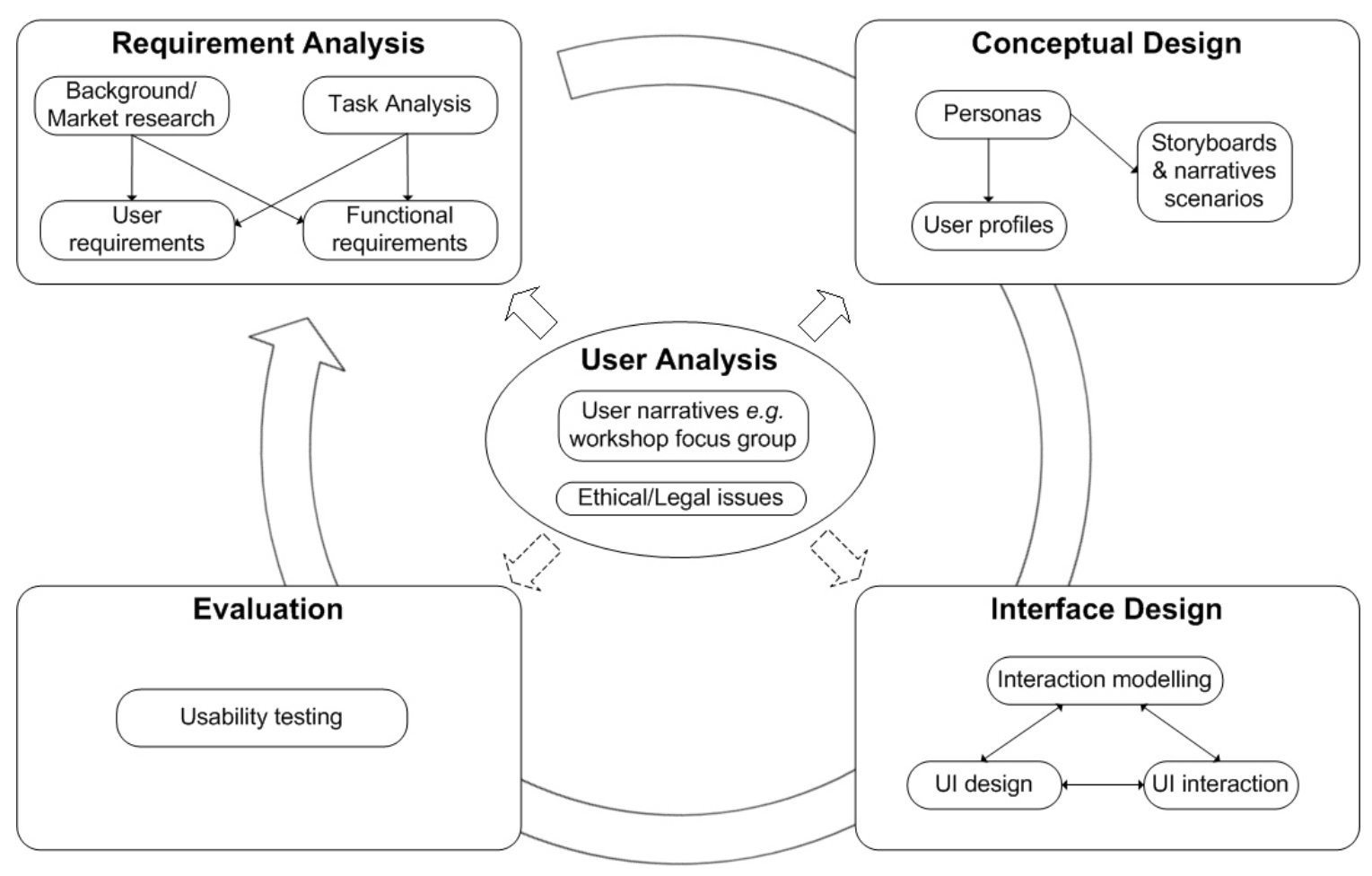

Figure 1a: Overview diagram of the EDUCATID methodology, showing the user analysis phase as the central hub. 


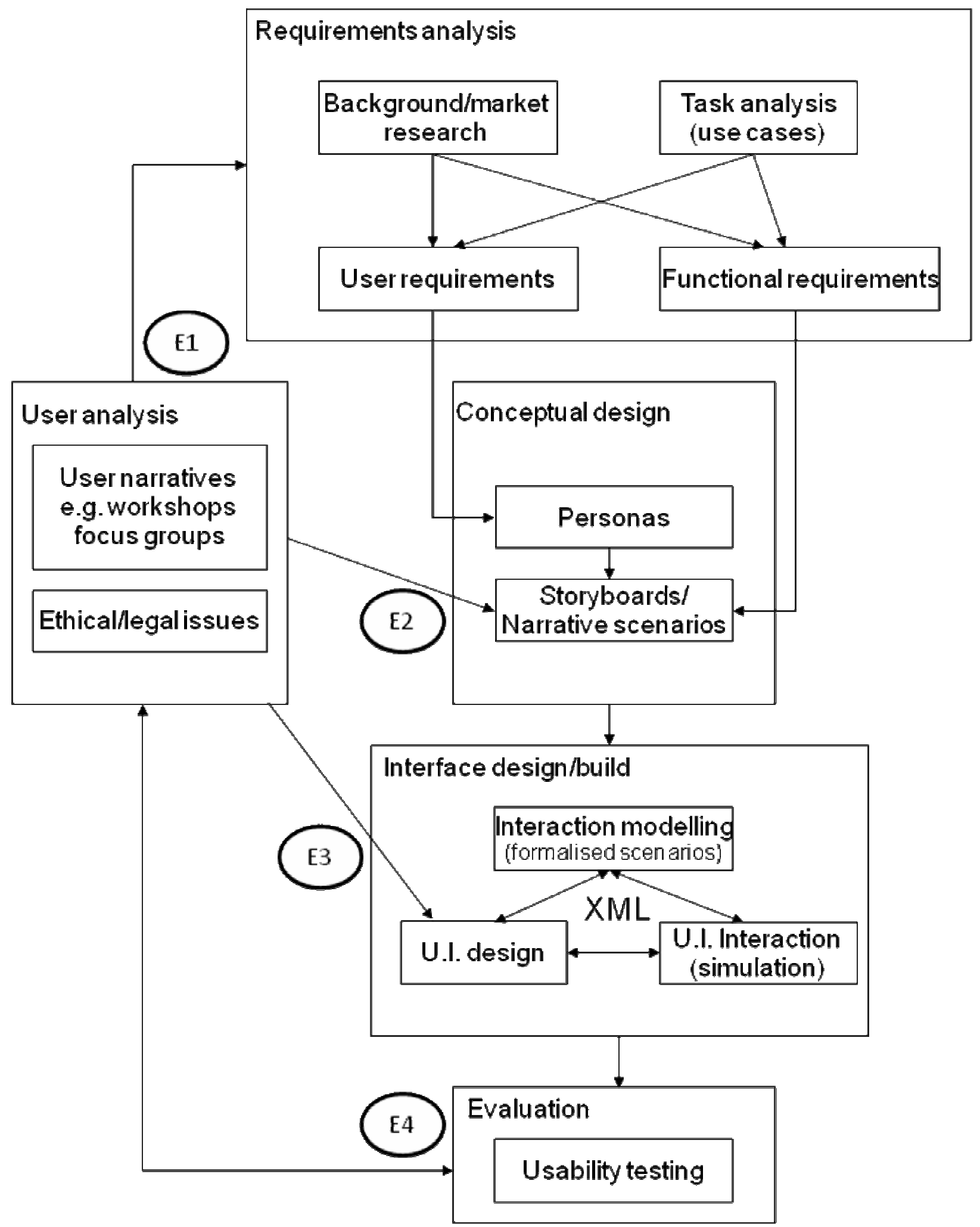

Figure 1b: Flow diagram for the EDUCATID methodology, showing ethical inspection points E1, E2, E3 and E4. 


\section{Initial requirements and user analysis}

The requirements analysis for EASYLINE PLUS began with a market and literature research exercise, in particular considering results disseminated by other European Projects, such as AutoHan [24], and products available commercially. Our initial analysis determined that although the technologies are currently available to realize smart kitchen environments, they are often expensive, tend to be aimed at a younger, technologically knowledgeable audience, and lack consistent user interfaces.

One of the fundamental objectives at this stage of the EASYLINE PLUS project was to identify the specific needs that elderly and disabled people have in their use of household appliances. To answer this question, open interviews of 80 elderly people were conducted to identify the problems encountered by users with limited abilities while using different household appliances. The records collected were then analysed by accessibility experts within the EASYLINE PLUS team.

The user analysis phase was launched in parallel with requirements analysis with an ethical and legal inspection of the anticipated project. We used the ethical triangle as a framework for this audit (figure 2). 


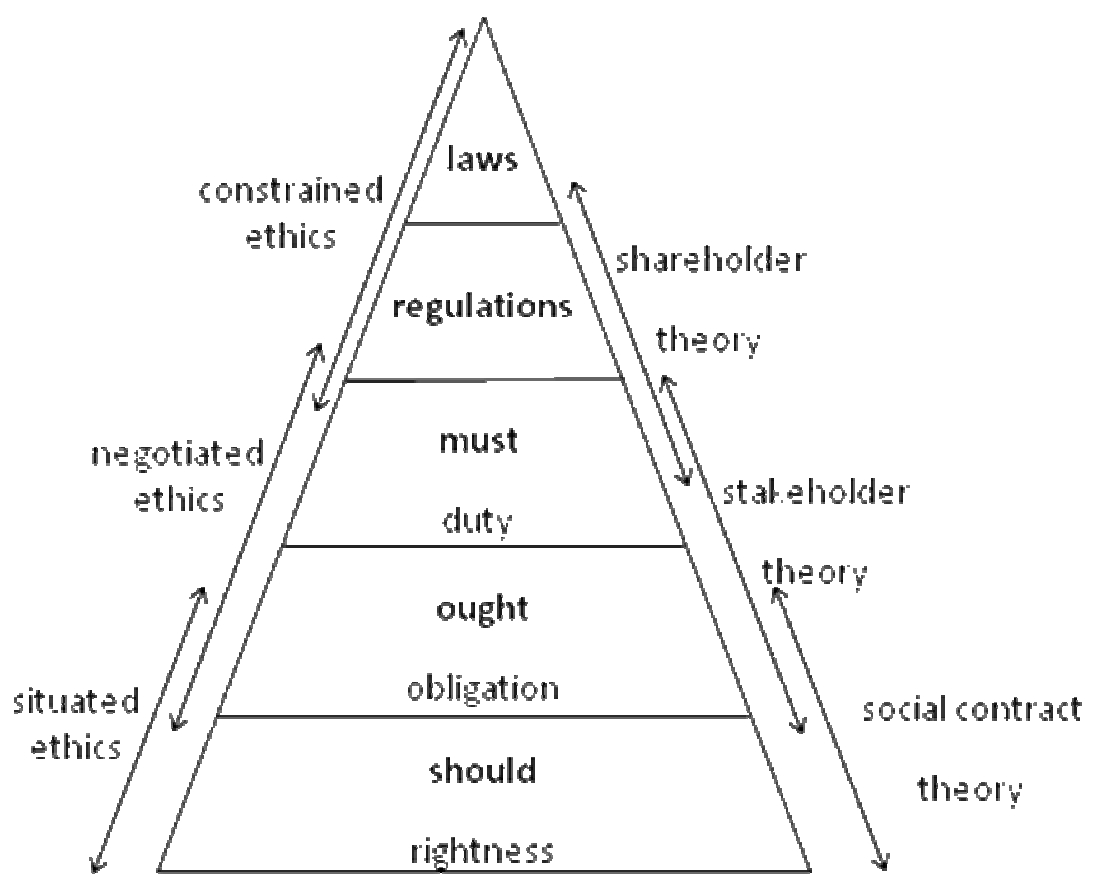

Figure 2: The ethical triangle ${ }^{1}$ [21]. Ethical considerations move from constrained, through negotiated and into situated, as the issues gravitate from the organizational to the individual. This conforms to the three normative theories of business ethics [25], which are listed on the right hand side of the triangle.

At the top of the triangle are laws and then regulations. These have to be considered first - hence they appear at the top of the diagram. These constrained ethics are usually generic, and may be set in law, ethical codes of practice, organizational regulations or professional and statutory requirements.

${ }^{1}$ The full title for this as proposed by the authors [21] is: The culturally negotiated ethical triangle. We use the short title in this paper for simplicity. 
Further down the triangle, those ethical factors regarded to be of high importance ("must") are considered - where those participating in the ethical audit agree that a duty is imposed, followed by those of middle importance ("ought") where an obligation is imposed. Finally, the factors deemed to be of some importance ("should"), where it is felt that it is right to proceed in a certain way, are considered. Generally, the number of considerations is expected to expand as we move down the list, hence the triangular shape. Also, although all factors of the triangle can be considered throughout the development process, it is likely that those nearer the bottom will become more prevalent over time. Hence, for this first iteration of user analysis, we concentrated on those factors which reside at the top of the triangle. In our project, this comprised scrutiny and validation by the Glyndwr University ethics committee which uses its own code of practice for ethical standards in research. Similar codes of practice may be obtained online through the British Psychological Society [26] and The British Sociological Association [27].

At this point, we combined Abascal and Nicolle's socially and ethically aware design guidelines with the factors on the ethical triangle. For our project, we considered where on the triangle each guideline should be placed. For example, the guideline: Minimise the use of 'fancy' or expensive technology was placed in the must category, as this is a fundamental requirement of the project; and the guideline: Avoid unnecessary automatic or external decisions by the system was placed in the ought category. Mapping each guideline onto the relevant factors of the ethical triangle provided us with a set of parameters which acted as a tool to verify ethically the ongoing development of the 
project. We used this approach at each iteration of the EDUCATID method, concentrating more each time on the lower levels of the triangle as the ethical issues became more situated in particular home environments for users with varying profiles.

Next, the first narratives workshop took place. For this, a wide set of participants was selected. Later iterations involved increasingly smaller groups, finally ending with a focus group for the last stage of the system's development. For our first workshop, five members of the EASYLINE PLUS team joined with a group of 10 experts from the fields of telecare, assisted living and smart home technologies, along with 14 service users and carers. Expert participants were represented from academia, the clinical sector, the social services, charities, and assisted living technology developers. During this event, typical usage scenarios were identified and described by both experts and service users (and their carers). The workshop participants separated into smaller breakout groups where they discussed and later presented issues relating to sensory impairment, cognitive needs, physical disabilities, well-being and everyday living. During the workshop, candidate user interface devices were also discussed. Four devices were considered appropriate candidates to display the user interfaces: a fixed device (the digital TV), a touch screen device, a mobile device (such as a Personal Digital Assistant (PDA) or a mobile phone) and an ambient device (e.g. a digital photo frame).

The television was chosen as the central information point since most people own a television, and they are generally familiar with interacting with it on a regular basis. The concept of using a television remote control to interact with other household appliances 
was also very popular, as long as it could be simple and intuitive to use. The idea of using the four coloured teletext buttons was also universally popular. This recommendation from the workshop concurred with the results from the open interviews conducted during the requirements phase. There was unanimous agreement that a single control unit to interact with all appliances would be a real leap forward in terms of usability.

A fixed touch screen monitor was also considered, as it could be situated in the kitchen or embedded in a wall. Generally, touch screens are popular with elderly adults, as long as the interactive buttons are of an appropriately large size [28]. However, such devices are still relatively expensive, and consequently these fell out of the scope of the EASYLINE PLUS project's constraint of affordability, and also broke the economic factors aspect of Abascal and Nicolle's socially and ethically aware design guidelines. Mobile devices are convenient and portable. However, the workshop participants rejected these devices as not well accepted by the current generation of elderly people due to the lack of familiarity, small-sized screen and the small keypad. Such failings are corroborated again by Abascal and Nicolle - in this case the first factor of design of inaccessible devices or services. Finally, an ambient device, such as an adapted digital photo frame was a very popular suggestion, as they are inexpensive and unobtrusive, and can be situated anywhere in the home. Workshop participants also discussed accessibility issues, and alternative interaction such as speech input and output were identified as clearly being important options. Task closure was seen to be a real issue for those with visual impairments, for example putting things away after using them, closing doors, and 
switching things off. Locating messaging devices in appropriate places to remind people about such things was discussed, for example by the bed, on the fridge door and so forth.

The workshop event and its outcomes proved to be highly useful, and this facilitated the next EDUCATID activity, where a task analysis using task flow diagrams and use cases helped to verify the shared understanding of how users with differing needs might interact with the appliances and their interfaces (figures $3 a$ and $3 b$ ). These graphical approaches proved to be simple and intuitive enough for most users and carers to comprehend during later verification with a sub-group of workshop participants. Subsequent to this exercise, the initial functional requirements for the system and the user requirements were drafted. 

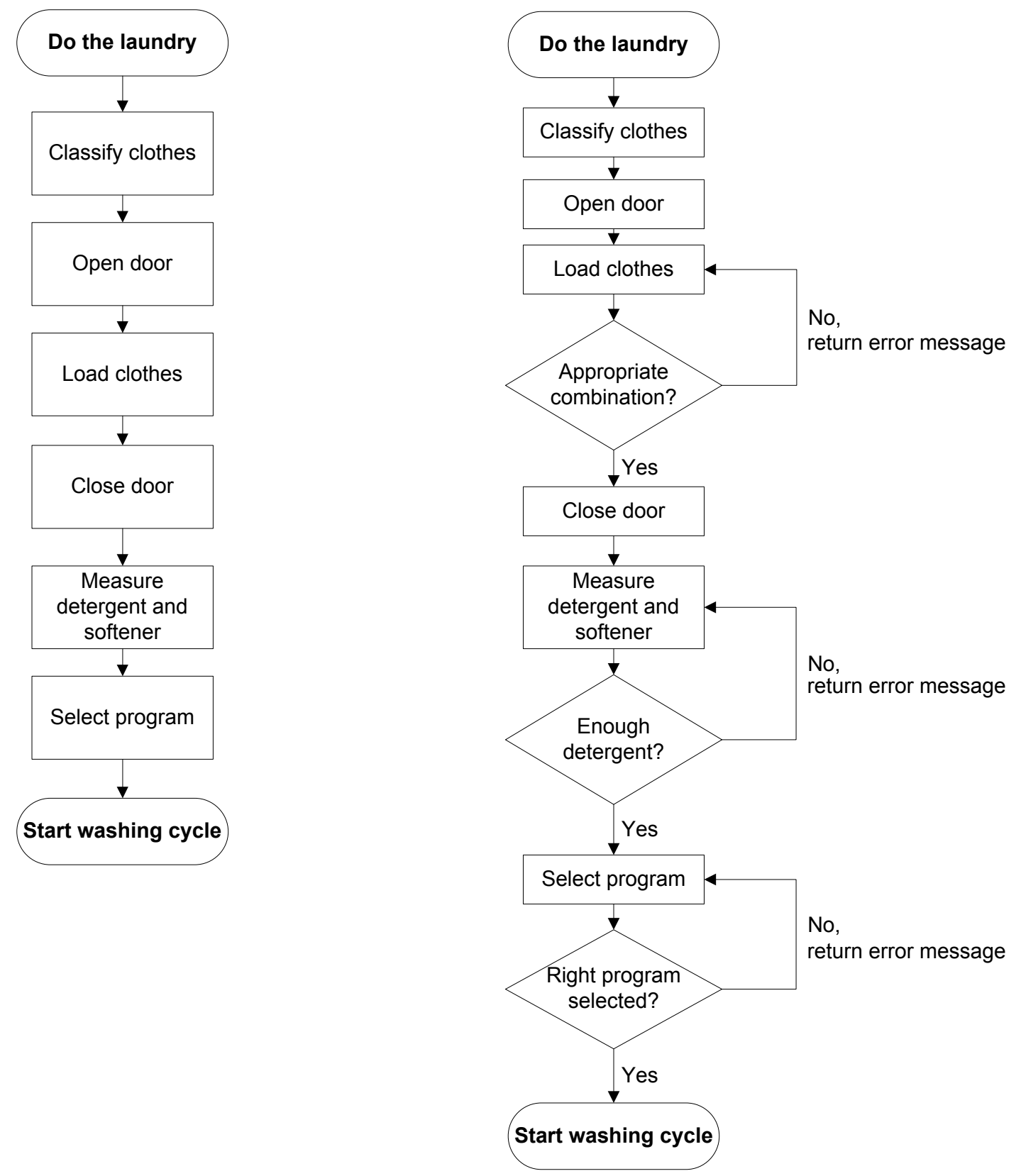

Figure 3a: Example task flow diagrams for doing laundry, displaying two modes of use for users with differing cognitive abilities. 


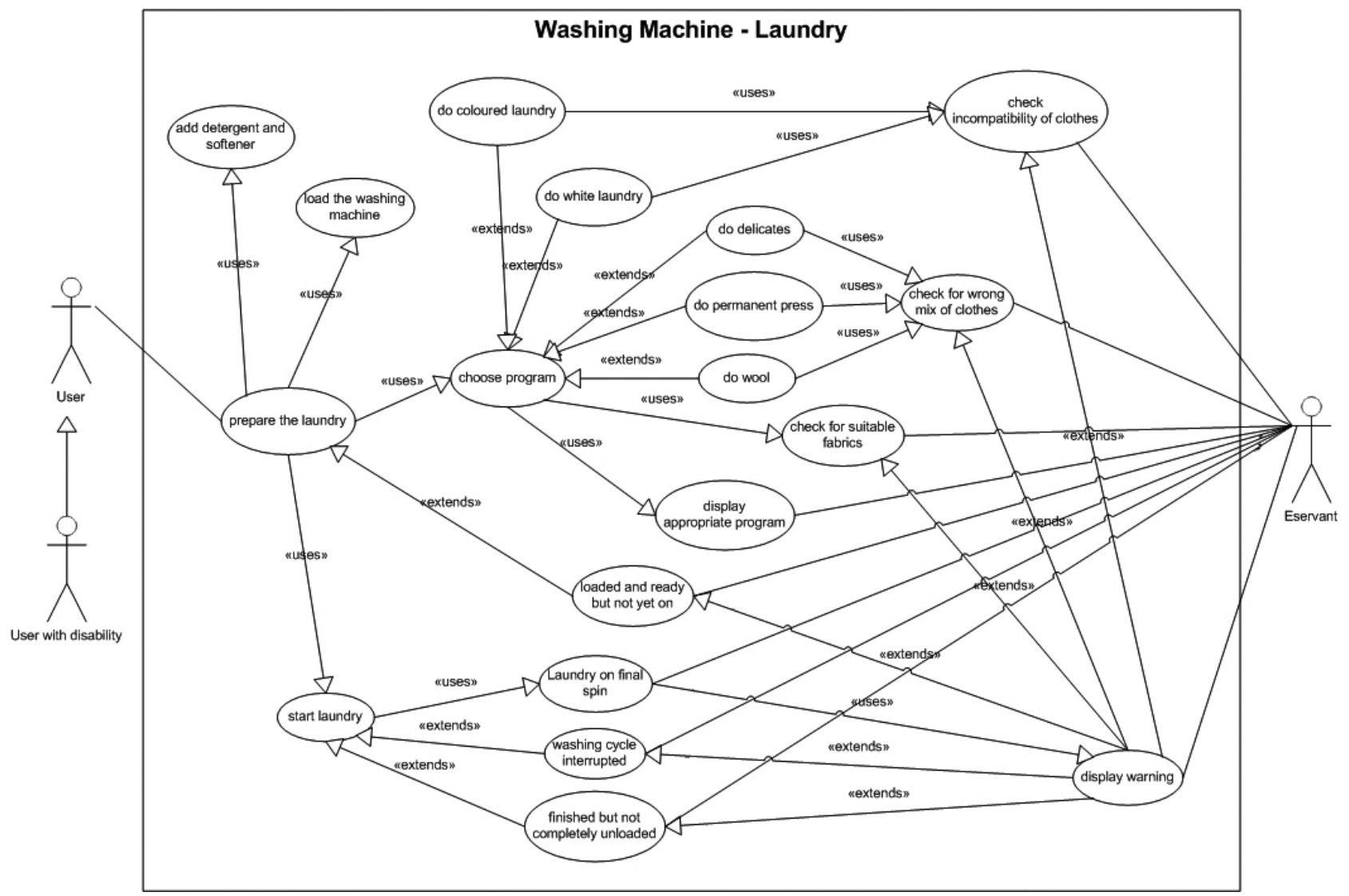

Figure 3b: Example use case diagram for advanced use of washing machine 


\section{Conceptual design}

The conceptual design phase began with the generation of personas. We specifically decided to formulate personas for EASYLINE PLUS as our user population is vulnerable, and to involve them in a more intensive participatory design approach may have caused ethical and practical problems. Such issues have been highlighted in the past, particularly by Newell and Gregor [29]. One possible solution to these problems has been successful, where trained performers role-play elderly adults [30]. However, a recognized drawback of this approach is that it can be expensive, hence our adoption of the more practical personas and scenarios techniques. We created ten personas based on our experience with service users in the narratives workshop, and also from data sources based on European

(Eurostat) statistics [31]. Characteristics such as age, education, work situation, impairment, and technology familiarity were assigned. Figure 4 represents one of the ten personas created. 


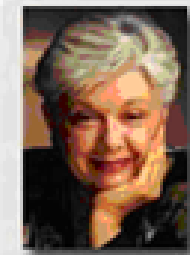

Hannah, 67 years old, Sweden

"I am looking for technologies that can bring me closer to my children...

Retired, Ex-secretary in a bank

Has a less upper secondary education

Wdowed, 1 daughter, 2 grandchildren
Suffers from mild impairement

Suffers from ostecarthritis

Owns a computer, no mobile phone.

Hanna used to work in a bank as the director's secretary. She is a computer literate but never was interested in becoming a power user. Her arthritis started when she was 55 due to the repetitive typing movements on the keyboard.

Hanna was married for 38 years when her husband died a couple of years ago of a lung cancer. She is now living by her own in a quiet residential area in the south of Sweden. She spends most of her time at home doing common household tasks that she hates to do. She enjoys listening to the opera, taking long walks with her dog Bandit, meeting and playing cards with her friends every weekend, cooking and talking for hours on the phone with her daughter Michelle who lives at two hours driving from her. Living alone is not easy, and Hanna likes to get company: her daughter visits with her 2 grandchildren Adam and Erika as often as they can but not as much as Hanna would like.

Hanna wears glasses to correct her visual impairment but she only wears them when she needs to read or do something that requires seeing up close... like playing cards with her friends. Her vision of things at distance is good. She installed a glass magnifier on her computer monitor so she does not have to wear her glasses and she is able to check her emails without any difficulty.

Figure 4: An example persona

Scenarios are short narrative stories describing the user's activities or tasks, often

described as prototypes built of words [32]. They can illustrate what someone is doing or how to accomplish something. We recorded a number of scenarios as described by participants in the narratives workshop and from the functional requirements.

We then converted these into simple to understand storyboards, using the personas as characters in each scenario, an example of which is shown in figure 5. This example was actually suggested by an elderly participant of the first narratives workshop. 


\section{Title: Out-Of-Date Product (OODP)}

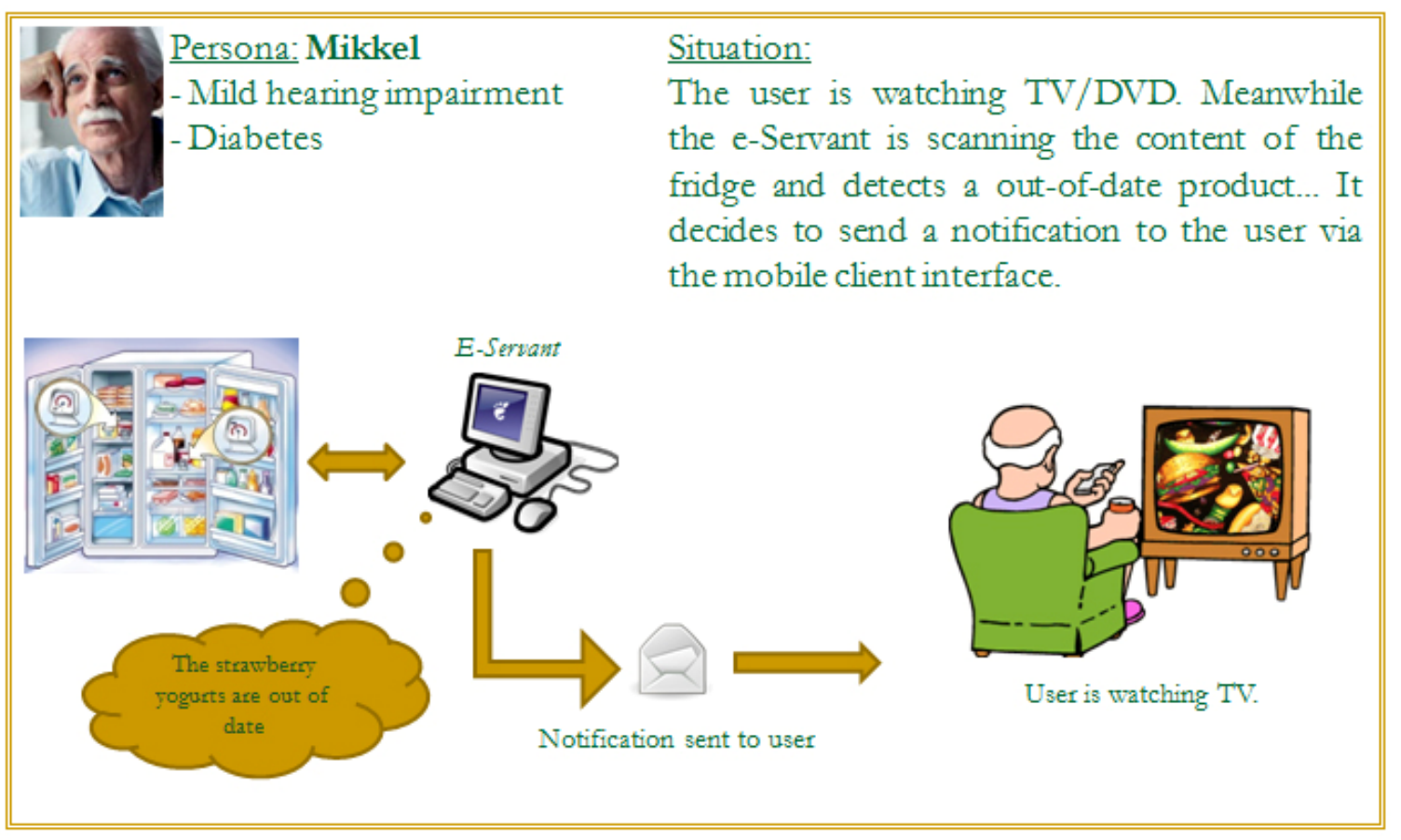

Appliance: Fridge

Case number: 1

Date: $12 / 09 / 2007$

Figure 5: An example storyboard, featuring persona Mikkel

The final activity of the conceptual design phase involved using the personas to create a more formal set of user profiles, which represented the typical range of users of the system. These profiles were represented in XML format, and incorporated directly into the e-servant's user profile database, to be used in executable form in the actual interface implementation. Our project identified a range of user profiles, including low-cognitiveability, typical-cognitive-ability, and high-cognitive-ability, and for each of the cognitive variations, a visual-ability factor was applied. The cognitive ability profiles of low and typical map onto the two higher scales of the three-tier Mini Mental State Examination [33] (the lowest tier of severe cognitive impairment would render any computer system 
virtually unusable for such people). It should be emphasized that any professional assessment of individual cognitive state was performed by clinical specialists outside the EASYLINE PLUS project. The initial profiles are adaptively tuned by the e-servant, which can modify certain attributes, such as the profile itself, how often to send reminders of open notifications, and the level of help provided by the interface.

\section{Interface design and build}

During the first activity in the interface design and build phase i.e. interaction modelling, we produced a semi-formalized representation of all scenarios in XML, which modelled the tasks users will undertake. This was carefully scrutinized to accommodate all functional requirements. Each task was modelled according to every user type, extracted directly from the user profiles. The interaction model was then integrated into the user interface design and the executable user interface interaction (at this point, in the form of a simulation). As this was at this stage of development a reasonably well-defined process, there was tight coupling between these three activities of the interface design and build phase.

In the EASYLINE PLUS project, a number of alternative prototypes were created. We determined that the usability principle of consistency should be adhered to in that the same interface should be presented on all output devices, and all input should be achieved by using a simple four icon display, as afforded by the coloured buttons on a TV remote control. On a future touch screen interface, these might be screen buttons. This constrained the interface design options somewhat, but facilitated a simple and intuitive 
solution. For the first iteration of the design and build phase of development, we decided on the design shown in figure 6.

The top part of the screen is used to display the status of each appliance, so the user can check quickly what is going on in the house. This area of the screen also serves as a tab to enable the user to step through the appliances to control them, or to review their status in more detail. The bottom part displays the four coloured buttons, and the middle part is the main frame where the content is updated dynamically to show information or give notifications and warnings to the user when events occur.

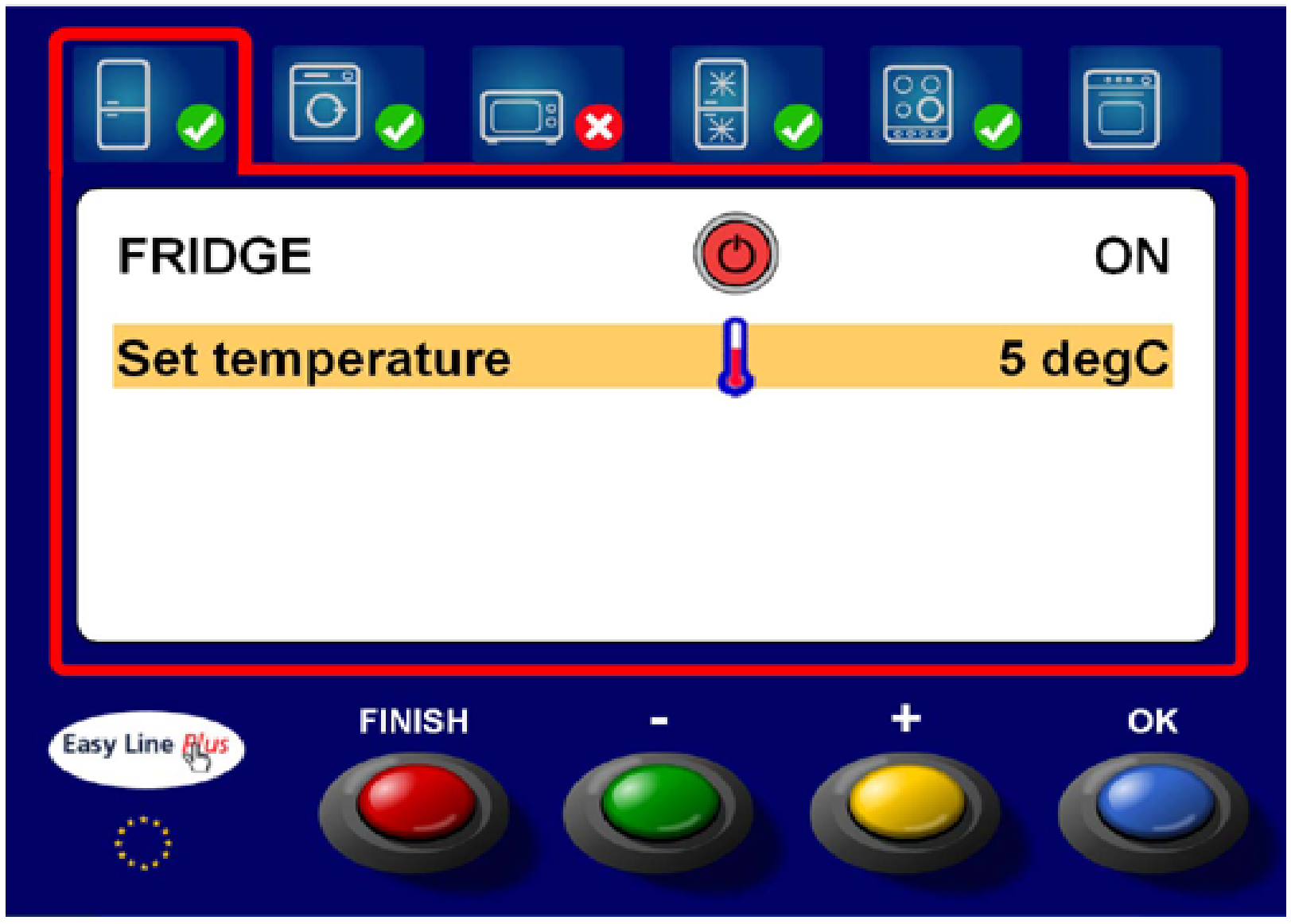

Figure 6. Prototype screen showing refrigerator settings control. 
At this stage and in accordance with EDUCATID, a further ethical inspection was undertaken, specifically with a view to ensuring accessibility. For the visually impaired user profile for example, all displayed messages and possible actions were now to be delivered in spoken form in the user's preferred language.

The interaction experience of the various user interface prototypes was tested during the user interaction activity. In EASYLINE PLUS, this was controlled through a user interaction simulator, designed and developed by the authors (figure 7). The simulator adhered strictly to an event, rule action protocol, which was read from the XML representation of the interaction model. 


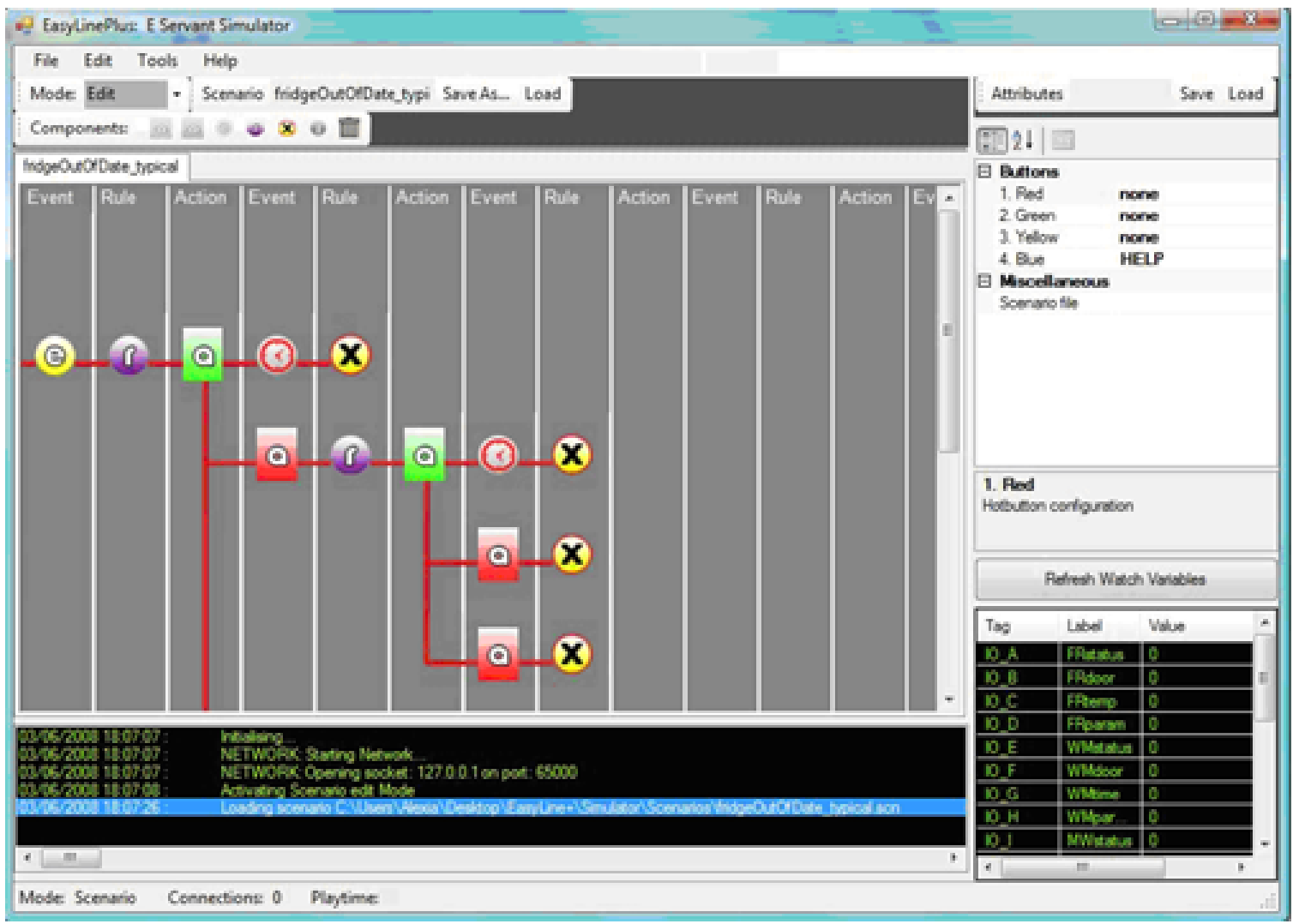

Figure 7: User interaction simulator

In the context of the EASYLINE PLUS project, the simulator acted as a proxy for the eservant. This facilitated the parallel development of external communication devices, such as user interfaces or appliances. The simulator enabled scenarios to be played out in real-time, and where the various available communication mediums between the simulator and the external communication devices could be evaluated. An example scenario might be that the power to the refrigerator has been lost. In such a case, the eservant sensed the problem, and the appropriate initiating event was triggered. Events were subsequently interpreted by a rule, which determined the nature of the action that was to follow. The different types of event maintained a common set of attributes such that rules could be used to determine a following action. In all, there were six constructs 
that could be combined together in a hierarchy to represent an executable scenario: start event, rule, action, timer, response, and termination event (figure 8).

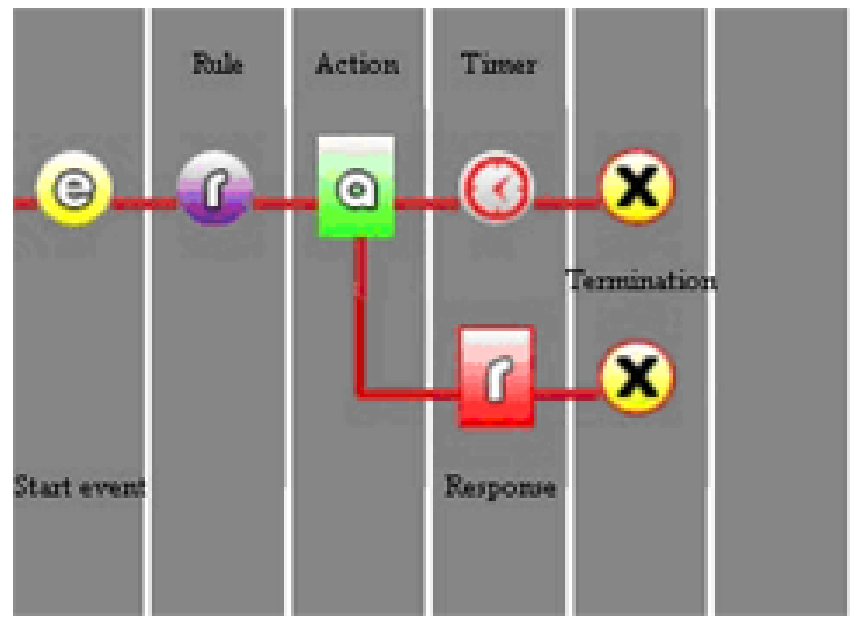

Figure 8: Simulator constructs

The simulator communicated with external devices using an XML message protocol. The first message in a scenario was usually sent by the simulator to an external device. Subsequently, the simulator expected one of several responses back from the external device, such as an acknowledgement from a user interface, or a change in status of an appliance. A timeout mechanism was provided to deal with the case where no response was obtained. There were two key message types used: action messages and response messages. Both these messages inherited the same common attributes.

This testing environment proved to be most useful in improving and refining the interface designs, the task sequences and analyses, and the robustness of the technologies used. 


\section{Evaluation}

For the EASYLINE PLUS project, we conducted laboratory-based studies initially, and during the second iteration of the method, the system was installed in an elderly person's actual home environment. Although the employment of usability laboratories for elderly users has been criticized [30], we found that with sensitive consideration, a usability lab does not have to be threatening or intimidating.

For our first instance of the evaluation phase - effectively the pilot testing, we furbished our laboratory in the style of a typical living room, using fixtures and fittings often found in an elderly person's accommodation, including the modified television set and a digital photoframe (figure 9). 


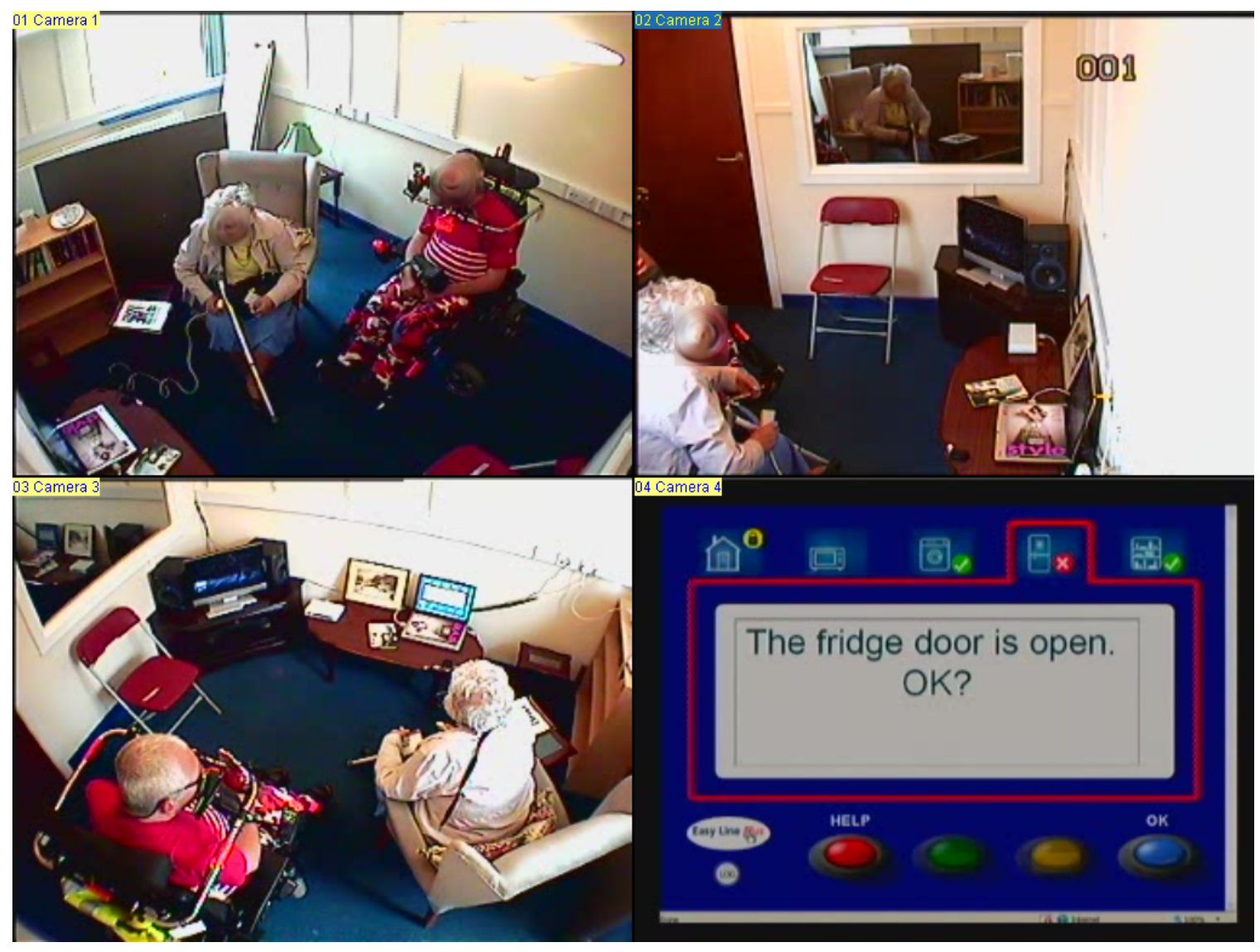

Figure 9. Usability laboratory showing an elderly and disabled participant interacting with the EASYLINE PLUS user interface (identities of participants have been protected through blurring of faces).

In our usability testing, we are bound by our own strict codes of ethical conduct, and our use of EDUCATID reminded us to adhere to them (for example, non-malificence, beneficence, confidentiality, informed consent, trust, honesty and integrity). Our approach at this stage was also mindful of making sure that participants felt supported, as well as comfortable in this environment. Consequently, the test facilitator accompanied them wherever necessary during experimentation. We used Dickinson et al's recommendations of measuring tasks completed with no assistance, with minimal 
assistance, and with significant researcher intervention [34]. We also considered it less intimidating if participants were tested in groups of two or three. Our participants were particularly pleased with this arrangement, especially where physical disabilities seriously restricted user interaction for some individuals.

The outcome of the first evaluation activity identified a number of potential usability issues, such as the loudness of audible warnings where people with varying profiles (for example, levels of deafness) shared the same user experience, the intrusiveness of the system (for example, potentially interrupting a television programme) and the size of the display, especially in the case of a photoframe. Generally, the participants welcomed the EASYLINE PLUS concept, and expressed that they would like to have such features installed in their homes. We have to be very mindful of such positivity however, as it is well documented certainly that elderly users feel valued in participating in usability studies, and are more likely than other users to provide positive answers in debrief sessions.

\section{Iteration of the method}

The results from the evaluation phase are used to re-visit the original requirements, where the cycle of phases begins again. We consider it imperative at this stage that ethical and legal issues are re-considered, and that a further workshop or focus group event is organized, hence the user analysis phase is undertaken again. The central theme of this engagement is to present the interface developments and use them to consult with end users and other stakeholders regarding their original scenarios. 
Our second workshop provided the 20 expert and service user participants with a presentation of the progress on the EASYLINE PLUS project, and invited contributions, suggestions and advice on improvements that could be made to the user interfaces. Providing users with more remote control of appliances, rather than of a subset of their features was a popular suggestion, as it was felt that this would be more empowering for users, as well as assuring a consistent user interface for all functions. This was an issue that was scrutinized and debated in our second ethical audit, which is described below.

For this exercise, the ethical triangle was again utilized. Unless there have been some relatively major new requirements changes since the first ethical inspection, it is unlikely that the laws and regulations factors will be important here. Now, the lower levels of must, ought and should take precedence, where the ethics may vary from situation to situation. For example, in the workshop, it was suggested that users should be able to control the oven hob remotely, supporting accessibility for physically disabled users. However, this could clearly lead to a potentially dangerous situation, if a hob is activated from another location. Consequently, it was agreed that a hob could be switched off remotely, but not on.

While this may be an obvious requirement from a health and safety point of view, a more contentious example follows: the EASYLINE PLUS interface enables a user to control a washing machine remotely (switch on/switch off), but the washing programme is set automatically by RFID transmission via tags sewn into the clothing. Workshop participants expressed a preference to override the automatic setting and set their own 
programmes remotely. This raised an interesting ethical dilemma, and caused us to revisit our initial ethical guideline that the system ought to avoid unnecessary automatic or external decisions by the system. In our initial requirements, it was determined that it would be in fact necessary to automate the washing programmes, as so many users expressed difficulty with this task. It now became apparent that what might be necessary for some users would be unnecessary for others. Consequently, this guideline was moved from the ought to the should category, and its invocation would depend on the user's situation (for example cognitive ability). This analysis at the level of situated ethics helped us to tune the profiling of users and their individual requirements.

With improved requirements, we then repeated the conceptual design phase, introducing new personas and scenarios where appropriate, and continued through to the interface design and build phase, where improvements to the original prototypes were made and solidified.

This second iteration of the EDUCATID methodology involved further laboratory studies where necessary, for example where alternative design solutions required scrutiny, or where scenarios had alternative models to be evaluated. Subsequently, we undertook a more summative usability evaluation exercise, both to evaluate the EASYLINE PLUS interface, and indirectly to evaluate the effectiveness of using the EDUCATID approach. We conducted between-groups laboratory-based usability studies with heterogeneous groups of users, including elderly and disabled users, people with learning difficulties, as well as with 'healthy' adults. We were interested in evaluating the latter group for two 
reasons. Firstly, it has been documented that elderly and vulnerable participants in usability studies may react differently than they normally would, for example by being over-positive due to their involvement in the study $[35,36]$. Comparing their results with what might be termed a control group would potentially identify issues of this nature. Secondly, our earlier evaluations suggested that the product might be suitable for timeimpoverished people (for example, stressed mothers with babies in the home), not just elderly and disabled people.

We selected a total of 27 participants for this evaluation exercise, comprising nine elderly users, nine with learning difficulties, and nine from the 'control' group. Fourteen participants were female, the other thirteen being male. Of the elderly group, one was aged over 80, four in their 70's, one in her 60's and three in their late 50's. All participants in this group had a range of physical and sensory impairments relating to conditions associated with aging. The learning group was recruited from a further education college which specializes in teaching people with learning disabilities. All these participants were below 50 in age.

Each group was given a set of scenarios to follow (for example loading the refrigerator, baking food, and doing laundry), which involved interaction with the kitchen appliances and the user interface, which for this study was provided on a television screen and a PDA. Participants' activities were recorded in the laboratory, and were subsequently analyzed. They were also asked to complete a usability experience questionnaire comprising 20 semantically-rated questions (appendix A), which were categorized 
according to usability, design and layout, functionality, user satisfaction, and expected future use. Each question also invited qualitative comments. A summary of the quantitative results is shown in table 2.

\begin{tabular}{|l|c|c|c|c|}
\cline { 2 - 5 } \multicolumn{1}{c|}{} & $\begin{array}{c}\text { Overall } \\
\text { Average }\end{array}$ & $\begin{array}{c}\text { Control } \\
\text { Average }\end{array}$ & $\begin{array}{c}\text { Elderly } \\
\text { Average }\end{array}$ & $\begin{array}{c}\text { Learning } \\
\text { Average }\end{array}$ \\
\hline Usability & 2.87 & 3.22 & 2.79 & 2.56 \\
\hline Design and layout & 2.71 & 2.90 & 2.71 & 2.54 \\
\hline Functionality & 2.67 & 2.89 & 2.74 & 2.44 \\
\hline User satisfaction & 3.00 & 3.33 & 3.08 & 2.48 \\
\hline Future use & 2.55 & 2.67 & 2.78 & 2.01 \\
\hline
\end{tabular}

Table 2: Mean results by questionnaire category (range is from low rating of 0 to high rating of 4).

The aggregated results for every category and for all groups clearly indicate a positive outcome for the usability experience questionnaire. All results were higher than the median value of two. It can be seen in every category that the control group scored highest, followed by the elderly group, with the learning difficulties group scoring the lowest in all cases, except in the 'future use' category, where the elderly group gave the most positive response. The higher scores given by the control group could be explained by this group's positive comments on the potential of the product, as opposed to its current benefits.

We also carried out an Analysis of Variance (ANOVA) of every question in the user experience questionnaire. This analysis revealed that there were no significant differences in the responses provided by the three groups $(\mathrm{F}=1.52, \mathrm{p}<0.05)$, apart from one question which asked whether they felt embarrassment at using the system. The control group and the elderly group expressed no embarrassment at using the interface, whereas some members of the learning difficulties group were uncomfortable with it from this 
point of view. In particular, two participants were visibly startled when a notification alarm sounded, and this clearly affected their experience. This was evident by their written comments on the questionnaire as well as in the observational analysis. The observational analysis also revealed that all groups reacted quickly and positively to system-generated notifications. The control group performed expectedly better in general, and the only observed usability issues involved elderly users' difficulty in using a standard remote control handset and the small-screened PDA, both of which are easily rectified by selecting alternative input and output devices. The outcome of this study was generally positive, further corroborating the success of EDUCATID's process at this stage.

The aforementioned study took place in parallel with the initiation of an ongoing longitudinal study in the field (situated in an elderly person's apartment), where issues of accessibility, acceptability and adaptivity of the complete system are measured.

Finally, the third and last iteration of EDUCATID acts as a relatively short closure and review exercise, where the user interfaces can be verified, inspected from an ethical point of view for the ultimate time, and accepted by the end users and stakeholder groups.

\section{Discussion and reflection}

Our journey through EASYLINE PLUS began with a recognition of the critical impact that ethics would have on a project of this nature. Consequently, we decided to place our ethical decision-making at the centre of our approach. Given the technical nature of the implementation of the system, this project falls into the socio-technical category, leading 
us to develop an approach starting with the social and ethical issues, and moving from an informal specification of the human-computer interaction through to a semi-formalized and executable interaction model, utilizing tools developed by the authors. We believe and have demonstrated that this approach is practical, understandable, and ecologically valid.

Although developed specifically for the case study presented here, EDUCATID can be used in the design and development of any consumer-oriented application, such as home entertainment systems, interactive televisions, domotics applications, and public domain kiosks. Consumer-oriented applications exhibit certain characteristics that conform to EDUCATID's philosophy. These characteristics are becoming much more prevalent in modern interactive computer systems. Their increasingly ubiquitous nature assures a wide-ranging user population. Consequently, ethical issues arise, as potentially vulnerable people may be exposed to their use, such as the elderly, the young, and the disabled. Another characteristic, again associated with a wide-ranging user population, is that the interfaces for such computers need to be easy to use, intuitive, accessible, and well-structured. Their ubiquity also requires them to be more embedded and ambient, perhaps in familiar appliances in the home, or resident in everyday devices. With adaptation, we believe the approach could be used in organizational, business, and other contexts.

Recognition that ethical issues are critical for interactive systems projects of this nature is one important issue, but providing developers with practical ways of considering these 
(given that many developers may lack training in ethics) is another. Our demonstration of the ethical triangle and its combination with ethical guidelines offers a practical solution to this problem, and the EDUCATID approach of including ethical analysis at every stage in the development cycle can help reinforce this practice. We do not seek to replace ethical expertise, but we argue that as most development teams do not possess such a quality, the tools presented here offer a practical alternative. Applying the ethical inspection tool was relatively simple. We developed a table of risk factors in the project and the stakeholders involved rated each one at EDUCATID's defined ethical inspection points using the ethical triangle's five point scale. An example of this is shown in table 3.

\begin{tabular}{|c|c|c|c|c|c|c|c|c|}
\hline $\begin{array}{l}\mathrm{ENx}=\text { ethical checkpoint in } \\
\text { EDUCATID at iteration } \mathrm{N} \text { and } \\
\text { stage } \mathrm{x} \text { of method. } \\
\text { RFn = risk factors from } \\
\text { requirements. }\end{array}$ & E1a & E1b & E1c & E1d & E2a & $\mathrm{E} 2 \mathrm{~b}$ & E2c & E2d \\
\hline $\begin{array}{l}\text { RF2 Configure appliance } \\
\text { a. Usability/accessibility } \\
\text { b. Freedom of control } \\
\text { c. Dangerous settings }\end{array}$ & $\begin{array}{l}\mathrm{M} \\
\mathrm{O} \\
\mathrm{L}\end{array}$ & $\begin{array}{l}\mathrm{M} \\
\mathrm{O} \\
\mathrm{L}\end{array}$ & $\begin{array}{l}\mathbf{O} \\
\mathrm{O} \\
\mathrm{L}\end{array}$ & $\begin{array}{l}\mathrm{O} \\
\mathrm{O} \\
\mathrm{L}\end{array}$ & $\begin{array}{l}\mathrm{O} \\
\mathrm{O} \\
\mathrm{L}\end{array}$ & $\begin{array}{l}\mathrm{O} \\
\mathrm{O} \\
\mathrm{L}\end{array}$ & $\begin{array}{l}\mathrm{O} \\
\mathrm{O} \\
\mathrm{L}\end{array}$ & $\begin{array}{l}\mathrm{O} \\
\mathrm{O} \\
\mathrm{L}\end{array}$ \\
\hline $\begin{array}{l}\text { RF3 Give advice } \\
\text { a. Causing alarm } \\
\text { b. Causing interruption } \\
\text { c. Trust }\end{array}$ & $\begin{array}{l}\sim \mathrm{O} \\
\sim \mathrm{S} \\
\mathrm{M}\end{array}$ & $\begin{array}{c}\sim \mathrm{O} \\
\mathbf{O} \\
\mathrm{M}\end{array}$ & $\begin{array}{l}\sim \mathrm{O} \\
\mathrm{O} \\
\mathrm{M}\end{array}$ & $\begin{array}{c}\sim \mathbf{S} \\
\mathrm{O} \\
\mathrm{M}\end{array}$ & $\begin{array}{l}\sim \mathrm{S} \\
\mathrm{O} \\
\mathrm{M}\end{array}$ & $\begin{array}{l}\sim \mathrm{S} \\
\mathrm{O} \\
\mathrm{M}\end{array}$ & $\begin{array}{c}\sim \mathrm{S} \\
\mathrm{O} \\
\mathrm{M}\end{array}$ & $\begin{array}{c}\sim \mathbf{M} \\
\mathbf{X} \\
\mathbf{M}\end{array}$ \\
\hline RF5 Affordability & $\mathrm{M}$ & $\mathrm{M}$ & $\mathrm{S}$ & $\mathbf{M}$ & $\mathrm{M}$ & $\mathrm{M}$ & $\mathbf{X}$ & $\mathrm{X}$ \\
\hline
\end{tabular}

Table 3: Results of the ethical inspections at each ethical inspection checkpoint in the EDUCATID lifecycle (2 iterations). Entries in the table conform to the ethical triangle attributes of Laws (L), Regulations (R), Must (M), Ought (O) and Should (S). An X indicates conflict between stakeholders, and a squiggle negates the attribute. Bold typeface indicates ethical drift, suggesting an ethical issue requires further scrutiny. 
In terms of the interfaces we have developed in the EASYLINE PLUS project, our adherence to ethical principles constrained our designs to a certain extent, but we regard this as a positive factor, because our simple, intuitive interface designs have been accepted with confidence by our user population.

Our experience of using EDUCATID leads us to compare its effectiveness with other user-centred approaches such as ISO13407 [37], KESSU [38, 39] and LUCID [40]. These approaches have many similarities with EDUCATID, in that they follow similar processes. However, they propose flexible frameworks or models upon which to build methodological processes and method selections, whereas EDUCATID provides specific analysis, design and development techniques which are distinctly integrated into the process (workshops, focus groups, use cases, task flow diagrams, personas, storyboards, scenarios, user models, and the ethical triangle). Whilst there is undoubtedly a need for flexible frameworks and models to enable individual projects to be tailored according to their differences, we argue that there is also a place for more rigid approaches like EDUCATID, which can be managed and applied practically, especially in situations where there may be a lack of usability expertise available.

The usability evaluation study reported in this paper, which indirectly evaluated the effectiveness of using the EDUCATID approach, suggests that this is a feasible methodology to use for user-centred projects, particularly where ethical issues are critical. Grounded in prioritizing ethical issues, EDUCATID is the only method with specific and multiple ethical checkpoints in the project development cycle. The application of ethical 
principles is recognized to be fundamental to professionalism in the discipline of computing, as emphasized in the British Computer Society's Royal Charter, which is empowered to:

“... establish and maintain a sound ethical foundation for the use of computers, data handling and information technology systems; and to adopt any lawful means conducive to the maintenance of a high standard of professional skill and conduct amongst members of the Society"

British Computer Society Royal Charter 1984, amended 2003, para. 3(b)

Although the adherence to this sound ethical foundation does not specifically mention the development of computer systems here, we should infer that high standards and expectations should apply to any practice within the field of computing. EDUCATID provides such a framework.

Like other user-centred design approaches, utilizing EDUCATID requires effort to engage with the user population throughout. This involves forming relationships with user groups and associations, who need to commit to be involved on a number of occasions in the development process. Such activity might be regarded by some as difficult, time-consuming and costly. We recognized this as an issue for the EASYLINE PLUS project, and incorporated the use of personas to help alleviate over-reliance on the engagement with user groups. For other projects, personas may be used to varying degrees without prejudice to EDUCATID's philosophy. 
Finally, recognizing and applying ethical principles to the degree advocated by EDUCATID might be criticized for adding time, effort and even bureaucracy to a project's development. We argue that although some extra effort is required, as the tools and processes presented in this paper are practical, simple to follow and clearly defined, the EDUCATID methodology provides a powerful approach to developing user interfaces.

\section{Conclusion}

In this paper, we have presented a case study of how an ethically-aware methodological approach can be used to develop user interfaces. We have found that although the application of ethical guidelines can constrain the designers' options, it can also lead to simpler and more intuitive solutions. The user interfaces we have designed are grounded in being familiar to the user population, a factor considered fundamental for universal usability [41].

Acceptance of technological innovations for elderly and vulnerable people is not only dependent on good design - they need to be affordable too. It seems certain that the cost of technology will reduce in the forthcoming years, as computer literacy and novel device familiarity improves. Such trends will provide us with new opportunities, as well as new challenges. There will be further practical and ethical problems to overcome. 
Predicting how elderly people's independence will be supported by technology is still not clear, although the level of investment into research in this area provides some indication of how important this issue has become. What is certain however, is that the changing population distributions we are experiencing mean that we have no choice but to find technological solutions to the problem of an ageing society.

\section{Funding}

This work was supported by the European Union funded framework 6 project

Easyline+:Low cost advance white goods for a longer independent life of elderly people. [INFSO-IST-045515]. 


\section{Appendix A: Usability experience questionnaire}

\section{Usability}

1. Do you think the product was easy to use?

\begin{tabular}{|l|l|l|}
\hline Very difficult & Difficult & Normal \\
\hdashline
\end{tabular}

2. Do you think it was easy to learn how to use the product?

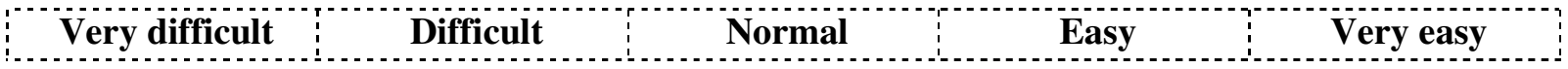

3. Do you think the product adapted to your particular needs and abilities?

\begin{tabular}{|c|c|c|c|c|}
$\begin{array}{c}\text { Totally does } \\
\text { not adapt }\end{array}$ & $\begin{array}{c}\text { Does not } \\
\text { adapt }\end{array}$ & Adapts & $\begin{array}{c}\text { Adapts } \\
\text { well }\end{array}$ & $\begin{array}{c}\text { Totally } \\
\text { adapts }\end{array}$ \\
\hline
\end{tabular}

4. How do you think the product reacts to the different input devices?

a. Touch screen

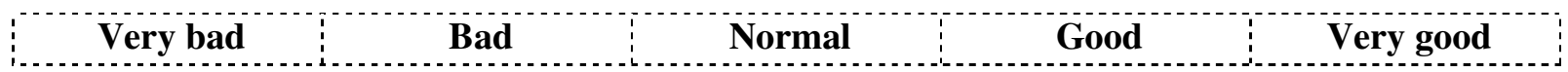

b. TV remote control

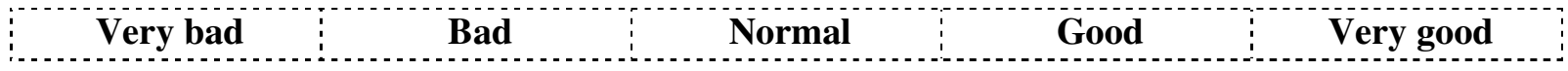

\section{Design and Layout}

5. Do you consider the product attractive?

\begin{tabular}{|c|c|c|c|c|}
\hline $\begin{array}{c}\text { Totally } \\
\text { unattractive }\end{array}$ & $\begin{array}{c}\text { Very } \\
\text { unattractive }\end{array}$ & Attractive & $\begin{array}{c}\text { Very } \\
\text { attractive }\end{array}$ & $\begin{array}{c}\text { Totally } \\
\text { attractive }\end{array}$ \\
\hline
\end{tabular}

6. Was the screen easy to understand?

\begin{tabular}{|l|l|l|l|}
\hline Very difficult & Difficult \\
\hline
\end{tabular}

7. What do you think about the sounds of the product?

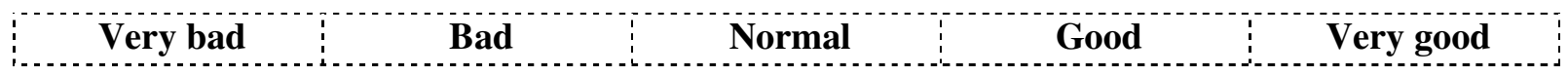

8. Do you think that the spoken notifications were comprehensible?

\begin{tabular}{|c|c|c|c|c|}
\hline $\begin{array}{c}\text { Totally } \\
\text { ncomprehensible }\end{array}$ & $\begin{array}{c}\text { Very } \\
\text { incomprehensible }\end{array}$ & nsible & $\begin{array}{c}\text { Very } \\
\text { comprehensible }\end{array}$ & $\begin{array}{c}\text { Totally } \\
\text { comprehensible }\end{array}$ \\
\hline
\end{tabular}




\section{Future use/outcome}

18. Do you think you might become dependent on the product if you use it in the future?

\begin{tabular}{|c|c|c|c|c|}
\hline $\begin{array}{c}\text { Great } \\
\text { dependence }\end{array}$ & $\begin{array}{c}\text { Much } \\
\text { dependence }\end{array}$ & $\begin{array}{c}\text { Some } \\
\text { dependence }\end{array}$ & $\begin{array}{c}\text { Little } \\
\text { dependence }\end{array}$ & $\begin{array}{c}\text { No } \\
\text { dependence }\end{array}$ \\
\hline
\end{tabular}

19. Do you consider that this product may isolate you from your actual social relationships?

\begin{tabular}{|c|c|c|c|c|}
\hline $\begin{array}{c}\text { Total } \\
\text { isolation }\end{array}$ & $\begin{array}{c}\text { Much } \\
\text { isolation }\end{array}$ & $\begin{array}{c}\text { Some } \\
\text { isolation }\end{array}$ & $\begin{array}{c}\text { Little } \\
\text { isolation }\end{array}$ & $\begin{array}{c}\text { No } \\
\text { isolation }\end{array}$ \\
\hline
\end{tabular}

Finally, how would you improve the product?

\section{References}

[1] Eurostat (2008) Demographic Change: Challenge or Opportunity?

http://epp.eurostat.ec.europa.eu/, accessed $16^{\text {th }}$ February 2009.

[2] MonAmi, http://www.monami.info/, accessed $16^{\text {th }}$ February 2009.

[3] OLDES, http://www.oldes.eu/, accessed $16^{\text {th }}$ February 2009.

[4] INHOME, http://www.ist-inhome.eu/, accessed $16^{\text {th }}$ February 2009.

[5] CAALYX, http://caalyx.eu/, accessed $16^{\text {th }}$ February 2009.

[6] Miskelly, F.G. (2001) Assistive technology in elderly care, Age and Ageing, Oxford Journal, 30(6), 455-458.

[7] Cook, D.J. (2007) Providing for older adults using smart environment technologies, IEEE USA Today's Engineer Online, 5(7), accessed 16 ${ }^{\text {th }}$ February 2009.

[8] Zajicek, M. (2000) Interface support for elderly people with impaired sight and memory, 6th European Research Consortium for Informatics and Mathematics (ERCIM) Workshop 'User Interfaces for All', CNR-IROE, Florence, Italy, 25-26 October. 
[9] Abascal, J. and Nicolle, C. (2005) Moving towards inclusive design guidelines for socially and ethically aware HCI, Interacting with Computers, 17 (5), 484-505.

[10] Mäyrä, F. and Vadèn, T. (2004) Ethics of Living Technology - design principles for proactive home environments, Human IT, 7(2), 171-196.

[11] Friedewall, M., Vildjiounaite, E., Punie, Y., and Wright, D. (2005) Privacy, identity and security in ambient intelligence: a scenario analysis, Telematics and Informatics, 24, $15-29$.

[12] Goodman, J., and Lundell, J. (2005) HCI and the older population, Interacting with Computers, 17 (6), 613-620.

[13] Abascal, J. (2004) Ambient Intelligence for people with disabilities and elderly people, ACM Special Interest Group on Computer-Human Interaction (SIGCHI), Ambient Intelligence for Scientific Discovery (AISD) Workshop, Vienna, April 25.

[14] Dishman, E. (2004) Inventing wellness systems for aging in place, IEEE Computer, 37(5), 34-41.

[15] Goodman, J., Brewster, S. and Gray, P. (2005) Not just a matter of design: key issues surrounding the inclusive design process, Proceedings of Include, Helen Hamlyn Research Centre, London, UK, April.

[16] Walsham, G. (1996) Ethical theory, codes of ethics and IS practice, Information Systems, 6, 69-81.

[17] Avison, D. E. (1991) MERISE: A European methodology for developing information systems, European Journal of Information Systems (1), 183-192.

[18] Martin, J. (1991) Rapid Applications Development, Macmillan, Indianapolis, USA. 
[19] Avison, D. E. and Fitzgerald, G. (2006) Information Systems Development methodologies, techniques \& tools (4th ed), McGraw-Hill.

[20] Sharp, H., Rogers, Y. and Preece, J. (2007) Interaction Design: Beyond HumanComputer Interaction (2nd ed), John Wiley and Sons.

[21] Oram, D. and Headon, M. (2002) Avoiding information systems failure: culturally determined ethical approaches and their practical application in the new economy, Ekonomika (Engineering Economics), 2 (28), 9-13.

[22] Wood, J. and Silver, D. (1995) Joint Applications Development (2nd ed), John Wiley and Sons.

[23] Cooper, A. (1999) The Inmates Are Running the Asylum (1st ed), Sams Publishing. [24] Blackwell A.F. and Hague R. (2001) AutoHAN: An architecture for programming the home, Proceedings of the IEEE 2001 Symposia on Human Centric Computing Languages and Environments, Stresa, Italy, 5-7 September, pp. 150-157.

[25] Smith, H. J. and Hasnas, J. (1999) Ethics and information systems: the corporate Domain, MIS Quarterly, 23 (1), 109-127.

[26] The British Psychological Society, http://www.bps.org.uk/, accessed $19^{\text {th }}$ February 2009.

[27] The British Sociological Association, http://www.britsoc.co.uk/, accessed $19^{\text {th }}$ February 2009.

[28] Zhao, X.J., Plocher, T. and Kiff, L. (2007) Touch screen user interfaces for older adults: button size and spacing, HCI International 2007, $12^{\text {th }}$ International conference on Human-Computer Interaction, Beijing, China, 22-27 July. 
[29] Newell, A.F. and Gregor, P. (2000) User sensitive inclusive design in search of a new paradigm. Proceedings of the first ACM Conference on Universal Usability, Arlington VA, USA, pp. 39-44.

[30] Newell, A.F., Carmichael, A., Morgan, M. and Dickinson, A. (2006) The use of theatre in requirements gathering and usability studies, Interacting with Computers, $\mathbf{1 8 ,}$ 996-1011.

[31] Eurostat (2008) Europa - Eurostat, http://epp.eurostat.ec.europa.eu/, accessed 31 ${ }^{\text {st }}$ January 2008.

[32] Saffer, D. (2007) Designing for Interaction: Creating Smart Applications and Clever Devices, New Riders, Berkeley.

[33] Folstein M.F., Folstein S.E. and McHugh P.R. (1975) "Mini-mental state". A practical method for grading the cognitive state of patients for the clinician, Journal of Psychiatric Research, 12(3), 189-98.

[34] Dickinson, A., Newell, A.F., Smith, M.J., Hill, R. (2005) Introducing the internet to the over-60's: developing an email system for older novice computer users, Interacting with Computers, 17 (6), 621-642.

[35] Eisma, R., Dickinson, A., Goodman, J., Syme, A., Tiwari, L., Newell, A. (2004) Early user involvement in the development of Information Technology-related products for older people. Universal Access in the Information Society, 3(2), 131-140.

[36] Park, D., Schwarz, N. eds. (2000) Cognitive Aging: A Primer. In Psychology Press, Taylor and Francis Group, Hove, p.238.

[37] ISO13407 (1999) Human-centered design processes for interactive systems, $1^{\text {st }}$ ed. 
[38] Jokela, T. (2001) Assessment of user centered design process as a basis for improvement actions, Department of Information Science, University of Oulu. [39] Jokela, T. (2008) Characterizations, requirements, and activities of user-centered design - the KESSU 2.2 model. In Law, L.C., Hvannberg, E.T. and Cockton, G. (eds), Maturing Usability: Quality in Software, Interaction and Value, Springer.

[40] Kreitzberg, C.B. (2008) The LUCID framework: an introduction, Cognetics Corporation.

[41] O'Connell, T. A. (2007) The why and how of senior-focused design. In Lazar, J. (ed), Universal Usability: Designing Computer Interfaces for Diverse Users, John Wiley \& Sons, Ltd., Chichester. 